\section{If only abstracts were more concrete!}

\author{
Phil Wiffen
}

The classic school report comment of 'could try harder' could be applied to many of the abstracts submitted with papers to EJHP.

It has been encouraging to see the quality and quantity of papers that have been submitted to EJHP improve over the last 3 years. My impression is that more pharmacists are seeking to publish their work and pharmacists who have not previously published have taken up the challenge. In an attempt to raise standards further, I want to focus on the abstract. One of the frequently seen weaknesses in original reports is the quality of the associated abstract. What do we want?

Abstracts should restate all the key points of your paper. It will receive far more attention than your main paper as many readers will not have the rights to access the full text. Abstracts are not easy to do well but are often left to the last minute-we all do it! It needs to be written when everything else has been done and because of this, it frequently ends up as a rushed job. In addition, it is necessary to distil some 3000 words down into no more than 250 words. You have probably taken a long time to get the main text written, so step back and give appropriate time to the abstract as this will improve the impact of your paper and make it more likely to be accepted by a journal.

Correspondence to Professor Phil Wiffen, Pain Research Unit, Churchill Hospital, Old Rd, Oxford OX3 7LE, UK; phil.wiffen@ndcn.ox.ac.uk
It needs to be remembered that abstracts are the front window on your research paper. How you present your abstract will affect the decision of a reader to move on to read or even purchase the main text. If they are not impressed, they may decide to move on to someone else's writing.

In $E J H P$, we ask that four items need to be covered explicitly, namely objectives, methods, results and conclusions.

The objective may be the same as in the main body of the paper but explain why it is important, make the study sound interesting and relevant so that it grabs attention. Put the objective in context by giving some background and perhaps mention some previous research.

The methods section can be simple but describes how you carried out the work. For example, if it is a trial or a survey then say so together with brief details of what you did.

Results are the key section. This is frequently the weakest section and often does not contain any results! This part needs to focus on the main result linked to the objective and provide some data if available-numbers not just percentages. It is not uncommon to see statements such as ' $80 \%$ responded' with a sample size (buried in the main report) of ten. Or 8/11 responded rather than $72.727 \%$ responded. By the way, make that $73 \%$ or $72.7 \%$.

The conclusion should be sensibly drawn from the results, do not oversell it as readers will dismiss your view and likely dismiss the whole work. I see many conclusions that reflect the opinion of the writer rather than the results.

Some do's and don'ts

Do put in key headings and appropriate descriptions under each

Do use plain language where possible

Do make sure the language flows well

Do print and reread

Do get someone else to read the abstract before sending

Do stick to the required length

Do carry out a spelling and grammar check

Don't introduce new information.

Don't put citations in the abstract

Don't use abbreviations

Don't express opinions

Abstracts can make a paper. If you have not written one before then look at others' work or get advice. The EJHP website has a podcast and webcast that you will find helpful.

Competing interests None declared.

Provenance and peer review Commissioned; internally peer reviewed.

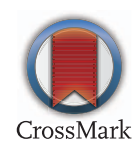

To cite Wiffen P. Eur J Hosp Pharm 2016;23:125.

Published Online First 23 March 2016

Eur J Hosp Pharm 2016;23:125.

doi:10.1136/ejhpharm-2016-000933 